\title{
Relation of the perception of airway obstruction to the severity of asthma
}

\author{
I D Bijl-Hofland, S G M Cloosterman, H Th M Folgering, R P Akkermans, \\ C P van Schayck
}

\begin{abstract}
Background-Patients with a poor perception of their symptoms of asthma seem to have an increased risk of an asthma attack. The influence of factors such as airway calibre, bronchial hyperresponsiveness, age and sex on the "perceptiveness" of a patient are poorly understood. It is of clinical importance to identify patients who are likely to have a poor perception of their symptoms. We have studied the perception of bronchoconstriction by asthmatic patients during a histamine provocation test and analysed the influence of bronchial obstruction, hyperresponsiveness, sex, and age. We were particularly interested to establish whether there was any difference in perception between subjects with a greater or lesser severity of asthma (expressed as bronchial obstruction, hyperresponsiveness).
\end{abstract}

Methods-One hundred and thirty four patients with allergic asthma underwent a histamine provocation test. The $\mathrm{FEV}_{1}$ was measured after each inhalation of histamine. Subjects were asked to rate subjective quantification of the sensation of breathlessness on a visual analogue scale (VAS). The relationship between changes in VAS values and the reduction in $\mathrm{FEV}_{1}$ as a percentage of the baseline value was analysed by determining the linear regression slope $(\alpha)$ between the two parameters and indicates the perception of airway obstruction. Multiple regression analysis was performed to investigate the effect of baseline $F E V_{1}$, bronchial hyperresponsiveness, sex and age on the "perceptiveness" for bronchoconstriction.

Results-The median value of the slope $\alpha$ (indicating the perception of airway obstruction) was 0.91 (25-75th percentile: $0.48-1.45)$. Age and sex had no influence on the perception of bronchoconstriction. Both initial bronchial tone (baseline FEV $_{1}$ ) and bronchial hyperresponsiveness $\left(\mathbf{P C}_{20}\right)$ showed a significant correlation with the perception of bronchoconstriction. The regression coefficients for $F E V_{1}$ and $2 \log \mathbf{P C}_{20}$ in the multiple regression model were 0.20 and 0.10 . Patients who had a low baseline $\mathrm{FEV}_{1}$ and/or a high bronchial responsiveness to histamine were more likely to show a low perceptiveness for bronchoconstriction during the challenge test.

Conclusions-Low baseline $\mathrm{FEV}_{1}$ and high bronchial responsiveness are associated with a low degree of "perceptiveness" for bronchoconstriction. This suggests that patients with a more severe degree of asthma either show adaptation of "perceptiveness" for airway obstruction or that low perceptiveness leads to more severe asthma.

(Thorax 1999;54:15-19)

Keywords: perception; airway obstruction; asthma

Some asthmatic patients perceive their symptoms of bronchial obstruction rather poorly. Patients with a poor perception might have an increased risk of a severe or even fatal asthmatic attack. ${ }^{1-3}$ Detection of the determinants of the ability of perceiving bronchial obstruction might be helpful therefore in protecting "poor perceivers" from a severe asthmatic attack. ${ }^{2}$ In this study we define perception of breathlessness as the subjective quantification of the respiratory stimulus intensity in relation to the bronchoconstrictive stimulus.

The bronchial challenge test with histamine was used to induce airway obstruction as a stimulus to measure the perceptiveness for the associated sensation. The reduction in forced expiratory volume in one second $\left(\mathrm{FEV}_{1}\right)$ as a percentage of the baseline value was used as an index for airway obstruction and the subjective quantification of the change in sensation of breathlessness was measured on a visual analogue scale (VAS). In line with other studies, the slope of the linear regression line $(\alpha)$ between these two parameters was used as an index of the "perceptiveness" of the patient ${ }^{4-6}$; the steeper the slope, the more sensitive a person is to signals of bronchoconstriction.

Subjects vary greatly in the subjective quantification of the stimulus at any level of the reduction in $\mathrm{FEV}_{1}$. The factors underlying this observed variability are still unknown. Some studies have shown an impaired perception by elderly patients ${ }^{7-10}$ but others have not. ${ }^{11}{ }^{12}$ Brand et $a l^{7}$ showed that women are more likely to perceive airway obstruction during a histamine challenge test than men. Furthermore, bronchial hyperresponsiveness has been found to be a possible factor in influencing the perception of asthma symptoms. ${ }^{67}$ Burdon et $a l^{6}$ suggested that those subjects who frequently develop acute airflow obstruction acquire a degree of tolerance that reduces the sensory intensity of the experience compared with that in less reactive subjects. Other studies have failed to show any influence of the severity of airway responsiveness on the perception of 
airway obstruction. ${ }^{1314}$ In daily practice it is especially important to identify non-perceptive subjects with a more or less severe degree of asthma (expressed as the baseline $\mathrm{FEV}_{1}$ and concentration provoking a fall in $\mathrm{FEV}_{1}$ of $20 \%$ or more $\left(\mathrm{PC}_{20}\right)$ ).

On the other hand, with reference to the $\mathrm{FEV}_{1}$, assuming a laminar flow in the airways, the driving pressure is proportional to the flow multiplied by the airway resistance. This means that flow $\left(\mathrm{FEV}_{1}\right)$ has a hyperbolic relationship with airway resistance. Consequently, a similar change in $\mathrm{FEV}_{1}$, from a high or a low baseline value, represents a relatively small or large change in airway resistance, respectively. Assuming that airway resistance is the adequate stimulus perceived by the patients, it would be reasonable to expect that subjects with a low baseline $\mathrm{FEV}_{1}$ might perceive the same decrease in $\mathrm{FEV}_{1}$ considerably better than subjects with a high baseline value of $\mathrm{FEV}_{1}$.

We have studied the perception of airway obstruction during a histamine challenge test on asthmatic patients to assess the influence of baseline $\mathrm{FEV}_{1}$, bronchial hyperresponsiveness, age, and sex. Specifically, we tested the hypothesis that subjects with a low baseline $\mathrm{FEV}_{1}$ are more likely to have a good perception of airway obstruction, because a similar change in $\mathrm{FEV}_{1}$ in these patients represents a relatively greater change in airway resistance than in subjects with a high baseline $\mathrm{FEV}_{1}$.

\section{Methods}

PATIENT SELECTION

Patients were recruited from a research project on symptom perception by asthmatic patients aged 16-60 years who were allergic to house dust mite. ${ }^{15}$ Inclusion criteria for this research project were $\mathrm{FEV}_{1}>50 \%$ of predicted value, $\mathrm{PC}_{20}$ histamine equal to or less than $8 \mathrm{mg} / \mathrm{ml}$ and/or reversibility of obstruction at least $15 \%$ after inhalation of $800 \mu \mathrm{g}$ salbutamol (compared with baseline $\mathrm{FEV}_{1}$ ), lower airway complaints, no use of oral steroids, and no dependency on inhaled corticosteroids. The present study was performed at the first assessment of lung function parameters after inclusion in the larger trial. Only patients with asthma with a baseline $\mathrm{FEV}_{1}>50 \%$ of the predicted value qualified for a histamine challenge test and were recruited for the present study. Patients had to have a bronchial provocation test with a minimum reduction in $\mathrm{FEV}_{1}$ of $20 \%$ or more of baseline value with at least two doubling doses of histamine to determine a patient's "perceptiveness" during this test. Informed consent was obtained from each patient.

BRONCHIAL PROVOCATION

Each patient underwent a histamine challenge test according to ERS standards. ${ }^{16}$ Prior to testing, no short acting bronchodilators were used for at least eight hours and no long acting bronchodilators for at least 12 hours. Doubling concentrations of histamine starting with $0.03 \mathrm{mg} / \mathrm{ml}$ up to $16 \mathrm{mg} / \mathrm{ml}$ were administered until $\mathrm{FEV}_{1}$ had fallen by at least $20 \%$ compared with the baseline value or a maximum of 16 $\mathrm{mg} / \mathrm{ml}$ histamine was given. The bronchial response to each dose of histamine was expressed as the reduction in $\mathrm{FEV}_{1}$ as a percentage of the baseline value according to ERS standards. ${ }^{16}$ The dose of inhaled histamine causing a $20 \%$ fall in $\mathrm{FEV}_{1}$ compared with the baseline value ( $\mathrm{PC}_{20}$ histamine) was obtained from the log-dose response curve by linear interpolation.

ASSESSMENT OF BREATHLESSNESS

Breathlessness was measured before each measurement of $\mathrm{FEV}_{1}$ using a visual analogue scale (VAS). The subjects rated their breathlessness on a $100 \mathrm{~mm}$ horizontal VAS with the words "minimum" and "maximum" on the left and right ends. Subjects were instructed that the word "minimum" meant "no complaints of respiratory sensation such as shortness of breath, chest tightness and breathlessness" and that "maximum" stood for "the worst complaints of respiratory sensation imaginable". The three different descriptions of symptoms (shortness of breath, chest tightness, and breathlessness) were all used as indicators of respiratory sensations. Subjects were asked to score the overall magnitude of all three symptoms together in one assessment. Other histamine related symptoms such as pharyngitis or conjunctivitis, headaches, or cough were not scored. The subjects were instructed to place a vertical mark on the line, such that its position relative to the two extremes indicated the magnitude of respiratory sensation at the moment of measurement. VAS values at any dose of histamine were expressed as absolute differences (in $\mathrm{mm}$ ) compared with the baseline value. ${ }^{17}$

\section{ANALYSIS OF DATA}

A patient's perception of bronchoconstriction was determined by the relationship between the absolute changes in VAS values in millimetres and the reduction in $\mathrm{FEV}_{1}$ as a percentage of the baseline value in each patient. This relationship was analysed by means of a linear regression coefficient (slope $\alpha$ ) between these two parameters in which the change in $\mathrm{FEV}_{1}$ was the independent variable and was placed on the $x$ axis. The change in VAS value, being the dependent variable, was put on the $y$ axis. Each $\left(\triangle \mathrm{VAS} / \triangle \mathrm{FEV}_{1}\right)$ slope indicates the perception of airway obstruction of that patient, the steeper the slope the more sensitive is the subject to signals of bronchoconstriction. Values are expressed as medians with 25-75th percentile ranges. $\mathrm{PC}_{20}$ values, which were positively skewed, were $2 \log$ transformed before this parameter was entered in the analysis. Multiple regression analysis was performed, with the perception of bronchoconstriction (slope $\alpha$ ) as the dependent variable and the baseline $\mathrm{FEV}_{1}, 2 \log \mathrm{PC}_{20}$, sex, age, and baseline VAS value as predictor variables. Predictor variables were entered in the multivariate model using a backwards procedure. A p value of $<0.05$ was regarded as statistically significant. 
Table 1 Clinical characteristics of the study population

\begin{tabular}{|c|c|}
\hline & Subjects $(n=134)$ \\
\hline Mean (SD) age (years) & $34(11)$ \\
\hline $\operatorname{Sex}(\mathrm{F} / \mathrm{M})$ & $61 / 73$ \\
\hline Geometric mean $(95 \% \mathrm{CI})$ range $\mathrm{PC}_{20}(\mathrm{mg} / \mathrm{ml})$ & $1.18(0.93$ to 1.49$)$ \\
\hline Mean (SD) $\mathrm{FEV}_{1}(\mathrm{ml})$ & $3229(724)$ \\
\hline Mean (SD) $\mathrm{FEV}_{1}(\%$ predicted) & $86(15)$ \\
\hline \multicolumn{2}{|l|}{ Smoking history: } \\
\hline Current smokers (pack years ${ }^{\star}$ ) & $25(10)$ \\
\hline Ex-smokers (pack years ${ }^{\star}$ ) & $30(13)$ \\
\hline Never smokers & 79 \\
\hline \multicolumn{2}{|l|}{ Medication used during 4 weeks prior for testing: } \\
\hline Beta $_{2}$ agonist (less than once a day) & 5 \\
\hline \multicolumn{2}{|l|}{$\begin{array}{l}\text { Combination of beta }{ }_{2} \text { agonist and anticholinergica } \\
\text { (Berodual) }\end{array}$} \\
\hline Less than once a day & 76 \\
\hline Regular (once a day or more) & 15 \\
\hline Regular anti-histamine (once a day) & 7 \\
\hline \multicolumn{2}{|l|}{ Beclomethasone nose spray } \\
\hline Less than once a day & 1 \\
\hline Regular & 1 \\
\hline
\end{tabular}

$\star 1$ pack year $=365($ days $) \times 20($ cigarettes $)$ ever smoked.

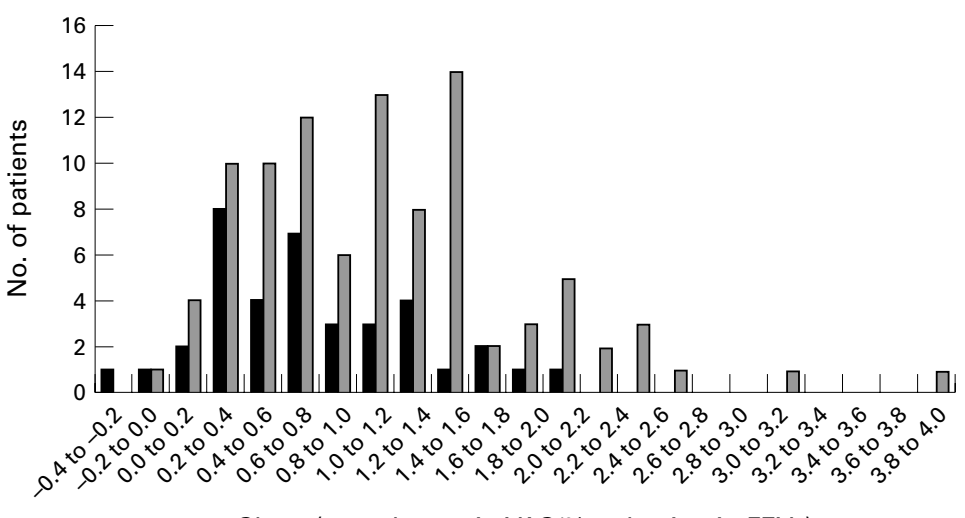

Slope ( $\mathrm{mm}$ change in VAS/\% reduction in $\mathrm{FEV}_{1}$ )

Figure 1 Histogram of the values of linear regression slopes (a) as index of the perception of bronchoconstriction. The slopes are assessed in the linear regression analysis as the change in VAS value according to the reduction in FEV as a percentage of the baseline value ( $n=$ 134). Solid bars represent patients with more severe asthma $\left(P C_{20} \leqslant 2 \mathrm{mg} / \mathrm{ml}\right.$ in combination with $F E V_{1} \leqslant 80 \%$ predicted); shaded bars represent patients with milder asthma $\left(P C_{20}>2 \mathrm{mg} / \mathrm{ml}\right.$ in combination with $\mathrm{FEV} V_{1}>80 \%$ predicted).

\section{Results}

PATIENTS

The clinical characteristics of the 134 asthmatic patients who could be analysed are presented in table 1 . Of the 162 subjects in the original trial, five had a baseline $\mathrm{FEV}_{1}$ of $<50 \%$ of the predicted value, one did not speak Dutch, in four patients no data on respiratory sensation were recorded, nine had a provocation test which consisted of only one doubling dose of histamine, and nine had a bronchial provocation test with a reduction in $\mathrm{FEV}_{1}$ of less than $20 \%$ of the baseline value. The total number of patients left for analysis was therefore 134 .

Table 2 Multiple regression analysis of perception of bronchoconstriction (indicated by the slope in the linear regression analysis between the change in VAS value and the reduction in $F E V_{1}$ as percentage of baseline value) according to baseline $F E V_{1}$, hyperresponsiveness $\left(2 \log P C_{20}\right)$, baseline VAS, age, and sex

\begin{tabular}{llll}
\hline & $\begin{array}{l}\text { Regression } \\
\text { coefficient }\end{array}$ & Individual $R^{2}$ & p value \\
\hline Intercept & 0.37 & & 0.179 \\
Baseline $\mathrm{FEV}_{1}(1)$ & 0.20 & 0.07 & 0.018 \\
Hyperresponsiveness (2log $\mathrm{PC}_{20}$ ) & 0.10 & 0.10 & 0.002 \\
Baseline VAS value (mm) & 0.04 & 0.00 & 0.652 \\
Age (years) & 0.03 & 0.00 & 0.777 \\
Male (0) female (1) & -0.01 & 0.01 & 0.870 \\
\hline
\end{tabular}

$\mathrm{R}^{2}$ of the total model $=0.14$.

Regression model: perception of bronchoconstriction $=0.37+0.10 \times 2 \log \mathrm{PC}_{20}+0.20 \times \mathrm{FEV}_{1}(\mathrm{l})$.
PERCEPTION OF BRONCHOCONSTRICTION

The subjects varied considerably in the subjective quantification of the stimulus at any level of the reduction in $\mathrm{FEV}_{1}$ as a percentage of the baseline value. The median value of the VAS value at the beginning of the histamine challenge test was $8 \mathrm{~mm}$ (25-75th percentile $2-18 \mathrm{~mm}$ ). The median change in the VAS value was $27 \mathrm{~mm}$ (25-75th percentile 19$39 \mathrm{~mm}$ ) and the median reduction in $\mathrm{FEV}_{1}$ as a percentage of the baseline value was $26 \%$ (25-75th percentile 23-31\%). The median maximum VAS value was $41 \mathrm{~mm}$ (25-75th percentile $26-58 \mathrm{~mm}$ ).

EFFECT OF AGE, SEX, PC $_{20}$ AND BASELINE FEV ${ }_{1}$ The index for the perceptiveness of bronchoconstriction quantified by the linear regression slopes $(\alpha)$ of the relationship between the reduction in $\mathrm{FEV}_{1}$ as a percentage of the baseline value and changes in VAS was made for 134 subjects (fig 1 ). The median slope was 0.91 (25-75th percentile 0.48-1.45). In fig $1 \mathrm{a}$ distinction has been made between patients with more severe asthma $\left(\mathrm{PC}_{20} \leqslant 2 \mathrm{mg} / \mathrm{ml}\right.$ in combination with $\mathrm{FEV}_{1} \leqslant 80 \%$ predicted) compared with the rest $\left(\mathrm{PC}_{20}>2 \mathrm{mg} / \mathrm{ml}\right.$ and/or $\mathrm{FEV}_{1}>80 \%$ predicted). The patients with more severe asthma differ from those with a milder degree of asthma ( $\mathrm{p}=0.005)$, with a median slope $\left(\Delta \mathrm{VAS} / \Delta \mathrm{FEV}_{1}\right)$ of $0.69(25-75$ th percentile $0.34-1.11$ ) and 1.08 (25-75th percentile $0.59-1.52$ ), respectively.

The result of the multiple regression analysis of the perceptiveness for bronchoconstriction according to baseline $\mathrm{FEV}_{1}, \mathrm{PC}_{20}$, baseline VAS, age, and sex are shown in table 2. Both initial bronchial tone (baseline $\mathrm{FEV}_{1}$ ) and the bronchial hyperresponsiveness (2log $\mathrm{PC}_{20}$ ) were positively correlated with the perception of bronchoconstriction. The regression coefficients for $\mathrm{FEV}_{1}$ and $2 \log \mathrm{PC}_{20}$ in the multiple regression model were 0.20 and 0.10 with $p$ values of 0.018 and 0.002 , respectively. This result indicates that patients with more severe airway responsiveness and/or low baseline $\mathrm{FEV}_{1}$ were more likely to show a lower perceptiveness for a decrease in $\mathrm{FEV}_{1}$ during a histamine challenge test than the more healthy subjects. The baseline VAS, age, and sex had no significant effect on the perception of bronchoconstriction.

\section{Discussion}

The results of the present study show that a low sensitivity to detect a decrease in $\mathrm{FEV}_{1}$ during a histamine challenge test was more likely to occur in patients with a relatively small initial airway calibre (lower baseline $\mathrm{FEV}_{1}$ ). This result is in contrast with the expectation that subjects with a low baseline $\mathrm{FEV}_{1}$ would perceive the same decrease in $\mathrm{FEV}_{1}$ better than subjects with a high initial $\mathrm{FEV}_{1}$, because a similar change in $\mathrm{FEV}_{1}$ in the latter group represents a relatively smaller change in airway resistance than in subjects with an initial low $\mathrm{FEV}_{1}$. Possible explanations might be that these subjects with a low initial airway calibre are chronically adapted to their increased airway resistance. Such an adaptive mechanism 
has been suggested by Burki et al and Turcotte et al. ${ }^{18}{ }^{19}$ Burki et al found that asthmatic patients appear to detect an inspiratory resistance less well than non-asthmatic subjects. ${ }^{18}$ Furthermore, Turcotte et al reported a poorly perceived late asthmatic response due to the mechanism of temporal adaptation during slow and progressive bronchoconstriction. ${ }^{19}$

An alternative explanation put forward by Roisman $e t a l^{4}$ is that increased inflammation, which is a possible cause of low airway calibre, influences the perception of induced bronchoconstriction. We were not able to measure the degree of airway inflammation to check this theory. Indeed, a positive association was found between the perception of airway obstruction and bronchial hyperresponsiveness. This result indicates that patients with more severe airway responsiveness (more inflammation) are more likely to show a low perceptiveness to a decrease in $\mathrm{FEV}_{1}$ than more healthy subjects. Although it is well known that bronchial obstruction and bronchial hyperresponsiveness are very much related, this can only partly explain the observations as the relationship between baseline obstruction and the perception of airway obstruction was corrected for hyperresponsiveness and vice versa. This finding might mean that patients with a high bronchial hyperresponsiveness experience airway constriction due to increased inflammation relatively more often and therefore may be more used to the sensation of breathlessness and more inclined to disregard the severity of the airway obstruction. These results show that patients with a more severe degree of asthma (low $\mathrm{FEV}_{1}$ and/or $\mathrm{PC}_{20}$ ) will perceive a further bronchoconstriction less than patients with a better baseline lung function. However, the opposite conclusion should also be considered-namely, that subjects with a poor perception did not demand sufficient treatment in the past which might have resulted in a more severe degree of asthma.

Regardless of the explanation, the percentage of explained variation of the total model was low $\left(R^{2}=0.14\right)$. This means that, although the severity of asthma seems to be a predictor, it may not be a major determinant of the perception of bronchoconstriction. Undoubtedly, there are many unknown factors that influence the perception of bronchocontriction which still have to be determined.

We did not find that the "perceptiveness" of a patient was influenced by age. This is in agreement with the results of a large study performed in six countries in which age and sex had no significant effect on the symptoms and the impact of asthma on daily living. ${ }^{11}$ Also, $15 \%$ of subjects in the study by Rubinfeld ${ }^{12}$ who were unable to perceive airway obstruction did not show any age or sex preference. However, these results and the result of the present study are in contrast with some other studies, where younger patients were more likely to perceive their dyspnoea during a histamine challenge test and during elastic loads. ${ }^{7-10}$ Connolly et al found that elderly subjects had an impaired perception and that the perception did not correlate with the degree of hyperresponsiveness. ${ }^{10}$ A possible reason for the different results is the chosen age distribution in the studies concerned. We studied subjects aged 16-60 years whereas the elderly patients in the study by Connolly were 60 years of age or older. An alternative explanation might be that the theory of "temporal adaptation" may only be relevant in the age range 16-60 years and the impaired perception in older patients may be caused by many other things. Several studies have reported impaired perception of bronchoconstriction by elderly subjects although the reason for this is by no means clear. ${ }^{1210}$ Furthermore, a few studies have shown that women report more dyspnoea than men $^{720}$ but others have not. ${ }^{112}$ The present study did not confirm any effect of sex.

The age range of our patients was 16-60 years. We excluded older patients in order to study asthmatic patients only and to exclude patients with COPD as far as possible. However, the exclusion of older patients could have affected the relationship between age and perception of bronchoconstriction.

Lougheed and coworkers found a strong relationship between inspiratory muscle work and the perception of asthma symptoms in patients with mild asthma. ${ }^{21}$ However, we studied asthma patients during a mean reduction in $\mathrm{FEV}_{1}$ of $27 \%$ of the baseline value in which no intensive muscle work can be expected. The perception of bronchoconstriction was therefore determined by the relationship between the changes in VAS values and the reduction in $\mathrm{FEV}_{1}$ as a percentage of the baseline value instead of the relationship between the symptom score and inspiratory capacity.

In conclusion, the perception of breathlessness during bronchoconstriction substantially varies between subjects and is weakly and positively correlated with $\mathrm{FEV}_{1}$ and $\mathrm{PC}_{20}$ but not with age or sex.

1 Barnes PJ. Poorly perceived asthma. Thorax 1992;47:408-9. 2 Barnes PJ. Blunted perception and death from asthma. $N$ Engl f Med 1994;330:1383-4

3 Kikuchi Y, Okabe S, Tamura G, et al. Chemosensitivity and perception of dyspnea in patients with a history of near-fatal asthma. N Engl f Med 1994;330:1329-34.

4 Roisman GL, Peiffer C, Lacronique JG, et al. Perception of bronchial obstruction in asthmatic patients. Relationship with bronchial eosinophilic inflammation and epithelial damage and effect of corticosteroid treatment. F Clin Invest 1995;96:12-21.

5 Marks GB, Yates DH, Sist M, et al. Respiratory sensation during bronchial challenge testing with methacholine, sodium metabisulphite, and adenosine monophosphate. Thorax 1996;51:793-8.

6 Burdon JGW, Juniper EF, Killian KJ, et al. The perception of breathlessness in asthma. Am Rev Respir Dis 1982;126: $825-8$.

7 Brand PLP, Rijcken B, Schouten JP, et al. Perception of airway obstruction in a random population sample. Relationhip to airway hyperresponsiveness in the absence of respiratory symptoms. Am Rev Respir Dis 1992;146:396-401.

8 Ward ME, Stubbing DG. Effect of chronic lung disease on the perception of added inspiratory loads. Am Rev Respir Dis 1985;132:652-6.

9 Tack M, Altose MD, Cherniack NS. Effect of aging on respiratory sensations produced by elastic loads. $\mathcal{f}$ Appl Physiol 1981;50:844-50.

10 Connolly MJ, Crowley JJ, Charan NB, et al. Reduced subjective awareness of bronchoconstriction provoked by methacholine in elderly asthmatic and normal subjects as measured on a simple awareness scale. Thorax 1992;47:

11 Quirk FH, Baveystock CM, Wilson R, et al. Influence of demographic and disease related factors on the degree of distress associated with symptoms and restrictions on daily living due to asthma in six countries. Eur Respir $\mathfrak{f}$ 1991;4:167-71. 
12 Rubinfeld AR, Pain MCF. Perception of asthma. Lancet 1976;24:882-4

13 Killian KJ, Summers E, Watson RM, et al. Factors contributing to dyspnoea during bronchoconstriction and exercise in asthmatic subjects. Eur Respir 7 1993;6:1004-10.

14 Turcotte H, Corbeil F, Boulet L-P. Perception of breathlessness during bronchoconstriction induced by antigen, exercise, and histamine challenges. Thorax 1990;45:914-8.

15 Schayck CPv, Cloosterman SGM, Hofland ID, et al. How detrimental is chronic use of bronchodilators in asthma and chronic obstructive pulmonary disease. Am $\mathcal{f}$ Respir Crit Care Med 1995;151:1317-9.

16 Sterk PJ, Fabbri LM, Quanjer PhH, et al. Airway responsiveness. Standardized challenge testing with pharmacological, physical and sensitizing stimuli in adults. Eur Respir f 1993;6:53-83.
17 Peiffer C, Toumi M, Razzouk H, et al. Relationship between spontaneous dyspnoea and lability of airway obstruction in asthma. Clin Sci 1992;82:717-24.

18 Burki NK, Mitchell K, Chaudhary BA, et al. The ability of asthmatics to detect added resistive loads. Am Rev Respir Dis 1978;117:71-5.

19 Turcotte H, Boulet L-P. Perception of breathlessness during early and late asthmatic responses. Am Rev Respir Dis 1993;148:514-8.

20 Janson-Bjerklie S, Kohlman Carrieri V, Hudes M. The sensations of pulmonary dyspnea. Nurs Res 1986;35:154-9.

21 Lougheed MD, Lam MIU, Forkert LUTZ, et al. Breathlessness during acute bronchoconstriction in asthma: pathophysiologic mechanisms. Am Rev Respir Dis 1993;148: $1452-9$. 